University of Nebraska - Lincoln

DigitalCommons@University of Nebraska - Lincoln

June 2003

\title{
Co-occurring forms of child maltreatment and adult adjustment reported by Latina college students
}

\author{
John C. Clemmons \\ University of Nebraska-Lincoln \\ David DiLillo \\ University of Nebraska-Lincoln, ddilillo@unl.edu \\ Isaac G. Martinez \\ Our Lady of the Lake University \\ Sarah DeGue \\ University of Nebraska-Lincoln \\ Michelle Jeffcott \\ University of Missouri-Columbia
}

Follow this and additional works at: https://digitalcommons.unl.edu/psychfacpub

Part of the Psychiatry and Psychology Commons

Clemmons, John C.; DiLillo, David; Martinez, Isaac G.; DeGue, Sarah; and Jeffcott, Michelle, "Co-occurring forms of child maltreatment and adult adjustment reported by Latina college students" (2003). Faculty Publications, Department of Psychology. 134.

https://digitalcommons.unl.edu/psychfacpub/134

This Article is brought to you for free and open access by the Psychology, Department of at DigitalCommons@University of Nebraska - Lincoln. It has been accepted for inclusion in Faculty Publications, Department of Psychology by an authorized administrator of DigitalCommons@University of Nebraska - Lincoln. 


\title{
Co-occurring forms of child maltreatment and adult adjustment reported by Latina college students
}

\author{
John C. Clemmons, University of Nebraska-Lincoln \\ David DiLillo, University of Nebraska-Lincoln \\ Isaac G. Martinez, Our Lady of the Lake University \\ Sarah DeGue, University of Nebraska-Lincoln \\ Michelle Jeffcott, University of Missouri-Columbia
}

Submitted December 2001; revised November 2002; accepted November 2002

\begin{abstract}
Objectives: This study had two primary objectives: First, to examine the nature and co-occurrence of various forms of child maltreatment (sexual, physical. emotional, and witnessing violence) reported by Latina college students, and second, to explore coexisting maltreatment types and acculturation status as possible contributors to long-term adjustment difficulties.
\end{abstract}

Method: Participants were 112 Latina undergraduate students categorized by the number of childhood maltreatment types experienced $(0,1$, or 2 or more) and acculturation level (1 to 5$)$. The possible effects of co-occurring forms of maltreatment, in conjunction with acculturation status, were investigated with respect to participants' reported trauma symptomatology. Data were collected using self-report measures.

Results: Nearly three out of 10 participants (29\% ) experienced more than one type of child maltreatment and, as expected, these individuals reported greater trauma symptomatology than those reporting either a single type of maltreatment or no maltreatment at all. Those who reported multiple types also endured more severe maltreatment than did respondents who experienced a single type. Acculturation level was neither directly related to trauma symptoms nor did it moderate the lasting correlates of maltreatment among victims. Interestingly, those who experienced a single form of maltreatment reported no more trauma symptoms than did participants who reported no maltreatment history at all.

Conclusion: This investigation documents a large degree of overlap among various forms of selfreported childhood maltreatment within a Latina college population. The results underscore the need to consider multiple forms of maltreatment, as well as severity, when making inferences regarding potential effects on later functioning.

Keywords: Child maltreatment, Sexual abuse, Co-occurring, Latina 


\section{Introduction}

A large body of research has examined the prevalence, characteristics, and potential consequences of various forms of child maltreatment, including sexual abuse, physical abuse, psychological abuse, neglect, and traumatic exposure to violence between parents. Historically, however, this literature has been segmented, with researchers tending to focus their efforts on a particular form of maltreatment to the exclusion of others. For example, most studies examining the long-term correlates of child sexual abuse have done so without considering concomitant forms of maltreatment experienced by children who are sexually victimized. Likewise, investigations of the lasting impact of childhood physical abuse have rarely assessed additional types of maltreatment.

Recently, an emerging area of research has begun to explore and document a co-existence between different forms of family violence and child maltreatment. As a whole, this work suggests that children who experience one type of maltreatment are at an increased risk of other forms as well. In an early examination of this phenomenon, Hughes, Parkinson, and Vargo (1989) found that $48 \%$ of 84 children residing in a battered women's shelter had not only been exposed to spousal abuse, but were also physically abused by a parent. This overlap between exposure to domestic "violence and child physical abuse has been found consistently across a number of subsequent studies, with overall rates of cooccurrence estimated at 40\% (see Appel \& Holden, 1998 for a review). Other researchers have found the co-existence of physical and sexual abuse in a sample of female inpatient adolescents to be 71\% (Westen, Ludolph, Misle, Ruffins, \& Block, 1990). Similarly, Claussen and Crittenden (1991) noted that $91 \%$ of 175 children reported to child protective services for physical abuse or neglect were ultimately found to have experienced both physical and psychological abuse.

The range of abuse types considered has recently been broadened by Higgins and McCabe (2000) who examined the co-occurrence of childhood sexual abuse, physical abuse, psychological abuse, neglect, and exposure to family violence reported by a community sample of 175 Australian men and women. Nearly half (43\%) of all participants reported experiencing more than one type of childhood maltreatment, while $15.4 \%, 11.4 \%, 9.7 \%$, and $6.9 \%$ of the total sample were classified as having experienced two, three, four, and five types of maltreatment, respectively. Similarly, in a study utilizing a large community sample of females in the US $(N=668)$, it was found that $53 \%$ of participants reported experiencing at least one form of child maltreatment (i.e., physical, sexual or emotional abuse) and $45 \%$ of the sample had endured two or all three types of abuse (Moeller, Bachman, \& Moeller, 1993).

\section{Potential impact of multiple abuse types}

Given the accumulating evidence of a co-occurrence of maltreatment types, it seems important to assess whether these experiences are related to increased symptomatology among victims. Initial studies with children suggest that those who are multiply victimized may be at risk of greater short-term symptomatology in comparison to youth who have not been abused or who have experienced a single form of maltreatment. Hughes et al. (1989) used the term "double whammy" to describe their findings that physically abused children who had also witnessed parental violence showed greater internaliz- 
ing and externalizing difficulties than did participants who experienced no maltreatment or those who had only witnessed parental violence. Other researchers have concluded that physical neglect, in conjunction with physical and verbal abuse, is particularly detrimental with regard to children's future outlook, whereas a combination of physical neglect, verbal, and sexual abuse was associated with decreased life enjoyment (Ney, Fung, \& Wickett, 1994).

The adult literature has also linked multiple childhood victimizations to long-term negative outcomes. For instance, women who report being physically and sexually abused as children may show more symptoms of PTSD, report increased sexual dysfunction, and experience more traumatic events in adulthood (e.g., sexual or physical assault, burglaries, serious injuries, or illnesses) than those with a history of a single type of child maltreatment or no maltreatment at all (Schaff \& McCanne, 1998; Wind \& Silvern, 1992). Other research has found that adults reporting three to five forms of child maltreatment had significantly higher levels of trauma-related symptoms and selfdepreciation than those who experienced one or two types of maltreatment (Higgins \& McCabe, 2000). Finally, the cumulative impact of child maltreatment may not be limited to psychological outcomes. Specifically, the likelihood of victims being hospitalized for illnesses and surgeries, and perceiving themselves as having physical difficulties, has been found to increase with the number of child maltreatment types reported (Moeller et al., 1993).

\section{Child abuse research with diverse populations}

To date, knowledge about the co-occurrence and cumulative impact of multiple forms of child maltreatment has been derived from studies involving almost long-term exclusively non-Hispanic Caucasian samples. This limitation is indicative of a broader trend revealed by a recent content analysis of the child maltreatment literature, which found that ethnic and cultural factors are often ignored in research on child abuse and neglect (Behl, Crouch, May, Valente, \& Conyngham, 2001). This failure to consider important demographic factors such as ethnicity highlights the need to incorporate diverse populations into the growing literature on co-occurring maltreatment types. Recent census figures showing a sharply increasing Hispanic population in the US (United States Census Bureau, 2001) underscores a particular need for the investigation of multiple forms of maltreatment within this burgeoning segment of society. Thus far, however, research with Latinos has mirrored the broader child maltreatment literature in its tendency to address single types of maltreatment, without considering the prevalence or possible combined effects of concurrent forms. For example, several studies have focused specifically on the occurrence and sequelae of childhood sexual abuse among Latinos (Arroyo, Simpson, \& Aragon, 1997; Huston, Parra, Prihoda, \& Foulds, 1995; Mennan, 1994; Sanders-Phillips, Moisan, Wadlington, Morgan, \& English, 1995), while other literature has examined physical abuse (Roosa, Reinholtz, \& Angelini, 1999; Schechter et al., 2000), or characteristics of psychological abuse (Champion, 1999).

Ethnic diversity is an important topic of investigation in child maltreatment research, in part, because factors associated with ethnicity may play a role in moderating the longterm impact of abuse. Ethnically based variables such as religiosity, social and family support, coping strategies, and treatment seeking, have the potential to help or hinder long- 
term adjustment to maltreatment. For instance, religion may help to provide a protective environment and encourage a perception of community support (Sorenson \& Siegel, 1992; Sue \& Sue, 1999) that may decrease psychological effects for Latinas who have experienced childhood maltreatment, especially sexual abuse. Conversely, it has been suggested that some religious beliefs may heighten victim-blaming responses, which may lower reporting rates and help-seeking by Latina victims, thereby contributing to deleterious psychological effects (Ramos Lira, Koss, \& Russo, 1999). Further, Latino cultures tend to hold more traditional values than the US dominant culture (Lefley, Scott, Llabre, \& Hicks, 1993), including an emphasis on the role of the family. An environment of familial support may encourage reporting and, in turn, help prevent long-term negative effects for victims of child maltreatment. In contrast, the traditional family values noted in many Latino populations may decrease reporting rates and victim support, as failure to protect an abusing relative could be considered a dishonor to the family (Ramos Lira et al., 1999).

Child maltreatment research with Latinos has typically focused on between-group comparisons among Latino and non-Hispanic Caucasian samples, with some investigations finding few ethnic differences in adjustment following abuse (Mannarino, Cohen, \& Gregor, 1989; Mennan, 1994) and others reporting that children and adults of Hispanic descent may suffer more serious symptomatology following abuse (Morrow \& Sorrell, 1989; Sanders-Phillips et al., 1995; Stein, Golding, Siegel, Bumam, \& Sorenson, 1988). However, this grouping together of individuals from particular cultural backgrounds to compare one ethnic group to another precludes a more thorough analysis of within group ethnically-based factors that may playa role in adjustment to childhood maltreatment (Fontes, 1995). One such factor is acculturation, or the degree to which Latinos identify with Anglo-American culture as opposed to their culture of origin. As with other factors related to ethnicity, investigations examining the effects of acculturation on various aspects of adult adjustment have yielded mixed results. For example, one study found no relationship between acculturation and depressive symptomatology among Latinos (Cuellar \& Roberts, 1997), while another revealed that acculturative stress may increase levels of depression among Hispanics (Rogler, Cortes, \& Malgady, 1991). To date, however, no studies have looked specifically at the potential impact of acculturation on outcomes for adult survivors of child maltreatment. A within-group examination of acculturation status can shed light on the role that affiliation with Anglo versus Latino culture may play in moderating the long-term correlates of childhood maltreatment.

The purpose of the present study is to add to the scant child maltreatment literature focusing on Latino populations by examining the nature and co-occurrence of multiple forms of childhood maltreatment in a sample of Latina college students. More specifically, childhood histories of sexual abuse, physical abuse, emotional abuse, and exposure to parental violence are examined in conjunction with acculturation status, as possible contributors to long-term difficulties in psychological functioning. Based on previous findings with non-Hispanic Caucasian samples, it is expected that those who recall experiencing multiple forms of maltreatment during childhood will report greater adult symptomatology in comparison to those who endured either a single form of maltreatment or no maltreatment at all. Additionally, it is predicted that acculturation status will moderate the relationship between the number of maltreatment types and participants' trauma symptomatology. 


\section{Method}

\section{Participants}

Participants were recruited by research assistants from undergraduate psychology classes at a private, urban university in south central Texas. This university serves primarily female students and thus the present study was limited to female participants. Approximately 150 students were invited to take part in the study and 112 agreed to participate. All participants were females of Mexican American descent who received class credit for their participation. The mean age of participants was $22.63(S D=7.25)$, with a range of 18 to 49 years. Of this sample, $90 \%$ reported being unmarried at the time of the study (i.e., they had never been married, were cohabiting, or were currently separated or divorced), while $10 \%$ were married at the time of their participation. Participants were asked to report their generation of Mexican American heritage. Generational levels used were from the Acculturation Rating Scale for Mexican Americans-II (ARSMA-II; Cuellar, Arnold, \& Maldonado, 1995). The number of participants endorsing each level was as follows: first generation ("You were born in Mexico or other country") $n=2$, second generation ("You were born in USA; either parent born in Mexico or other country") $n=38$, third generation ("You were born in USA, both parents born in USA and all grandparents born in Mexico or other country") $n=20$, fourth generation ("You and your parents born in USA and at least one grandparent born in Mexico or other country with remainder born in the USA") $n=29$, and fifth generation ("You and your parents born in the USA and all grandparents born in the USA") $n=30$. Generation ratings were not available for two participants. The Hollingshead Four Factor Index of Social Status (Hollingshead, 1975) was calculated for each participant and indicated a range of scores from 8.00 to 66.00 with a mean of $36.56(S D=11.69)$ for this sample, suggesting that the typical participant was of a lower-middle to middle socioeconomic background.

\section{Measures}

Child Maltreatment Interview Schedule-Short Form (CMIS-SF; Briere, 1992). The CMISSF utilizes a self-report format to assess experiences of childhood maltreatment in four main categories: sexual abuse, physical abuse, emotional abuse, and witnessing domestic violence. The CMIS-SF contains sections to assess the presence, frequency, duration, and severity of each of these childhood abuse experiences. Participants in this study were classified as having either experienced or not experienced each form of maltreatment based on the following definitions:

- Sexual abuse. Participants who reported experiencing (before the age of 17) sexual touching, sexual kissing, or oral, anal, or vaginal intercourse or penetration with a family member or a person who was 5 or more years older were considered victims of sexual abuse for the purposes of this study. Sample items from this subscale are as follows: "Before age 17, did anyone ever kiss you in a sexual way, touch your body in a sexual way, or .make you touch their sexual parts?" and "If yes, did this ever happen with someone 5 or more years older than you were?" 
- Physical abuse. Participants who reported that before age 17 a parent did something to them on purpose (i.e., hit, punched, cut, or pushed them down) that made them bleed, gave them bruises or scratches, or broke their bones or teeth on at least three occasions or to the extent that medical attention was required were considered victims of childhood physical abuse. A fairly conservative definition of physical abuse was utilized in order to minimize false positives resulting from the use of relatively common physical punishment (e.g., spanking) that could on occasion result in scratches or mild bruising.

- Emotional abuse. The emotional abuse section of this measure asks participants to rate how often before age 17 they were exposed to various parental acts that could be considered emotionally abusive (e.g., ridicule or humiliate you, yell at you, make you feel bad about yourself, etc.). Each of the 7 items on this scale is rated on a 7-point Likert scale ranging from $0=$ "never" to $6=$ "over 20 times a year" (Briere \& Runtz, 1988). Coefficient alpha for this scale was calculated at .914 for the present sample. Participants whose average rating across the 7 items fell above the scale mean of 3.5 were considered to have experienced emotional abuse in their youth. Participants classified as emotionally abused indicated that they were exposed to the events listed, on average, five or more times per year. This cutoff was selected, in part, to balance the number of false positives and false negatives in this category.

- Witnessing violence. Participants who reported "seeing one parent hit or beat up their other parent" before age 17 were considered to have witnessed violence as a child. Those who indicated that they had witnessed parental violence provided further information regarding the severity of these incidents by answering questions such as, "Did one or more of these times result in someone needing medical care or the police being called?"

Trauma Symptom Checklist-40 (TSC-40; Briere \& Runtz, 1989; Elliott \& Briere, 1992). The TSC-40 consists of 40 items that assess adult symptoms associated with traumatic childhood or adult experiences. Respondents use a four-point scale (from $0=$ "never" to 3 = "often") to rate the frequency with which they have experienced each symptom during the past 2 months. The TSC Total score demonstrates strong internal reliability (alphas ranging from .89 to .91; Briere \& Runtz, 1989; Elliott\& Briere, 1992) and was selected as the primary outcome variable for the study. The TSC-40 and its predecessor, the TSC-33, have also shown predictive validity with reference to abroad range of traumatic experiences, including being a victim of intimate violence (Dutton, 1995) and vicarious traumatization in psychotherapists with large caseloads of traumatized clients (Chrestman, 1995).

Acculturation Rating Scale for Mexican Americans-2nd Edition (ARSMA-II; Cuéllar et al., 1995). The behavioral aspects of Mexican American acculturation were assessed using the ARSMA-II. Sample items tapping these aspects of acculturation include: "I enjoy Spanish language movies," "My family cooks Mexican foods," and "My friends, while I was growing up, were of Mexican origin." The content of certain items (e.g., "I have difficulty accepting some of the beliefs held by Anglos") also allows for indirect assessment of the affective or cognitive dimensions of acculturation. The self-report, bilingual format of this measure allows participants to read each item in either English or Spanish, then rate how well the item applies to them on a 5-point Likert scale from $1=$ "not at all" 
to 5 = "extremely often or almost always." Two independent scales assessing acculturation, a 30-item Anglo Orientation Score (AOS) and a 17-item Mexican Orientation Score (MOS), measure the degree of affiliation with each culture in terms of language use and preference, ethnic identity and classification, cultural heritage and ethnic behaviors, and ethnic interaction (Cuellar et al., 1995). By subtracting the mean MOS from the mean of the AOS, a single linear score representing an individual's level of acculturation on a continuum from very Mexican-oriented to very Anglo-oriented can be obtained (Cuellar et al., 1995). Cuellar and colleagues (1995) report strong test-retest and internal reliability coefficients for the AOS and the MOS subscales (ranging from .86 to .96). Studies using factor analysis and cross-generation data provide support for the construct validity of the ARSMA-II in demonstrating consistent score differences between cohorts of Mexican American student populations (Cuellar et al., 1995).

\section{Procedure}

The data included in this study were collected as a part of a larger project exploring adult adjustment as it relates to a history of childhood maltreatment. IRB approval was obtained at both the institution where data collection occurred as well as at the institution of the primary study author. Prior to data collection, trained research assistants read informed consent forms aloud and participants signed them. Self-report questionnaire data were then collected from students in group sessions scheduled outside of regular class hours. Participants completed the CMIS-SF, TSC-40, and the ARSMA-II, as well as several other instruments not included in this study. All participants completed the instruments in a random order. This study was conducted in accordance with the American Psychological Association's ethical guidelines (American Psychological Association, 1992).

\section{Results}

\section{Data analytic strategy}

As noted, a primary objective of the investigation was to examine the potential impact of the number of maltreatment types and acculturation status on adult trauma symptomatology. This necessitated dichotomizing each form of child maltreatment (i.e., abuse either did or did not occur) and creating a summary score reflecting the total number of abuse types experienced by each participant. This score, in conjunction with acculturation level, served as grouping variables for conducting ANOVAs to test between-group differences and possible interactive effects on trauma symptoms.

\section{Maltreatment characteristics of the sample}

Specific characteristics of various types of maltreatment are presented in Table I; high lights of these results are noted here. Regarding sexual abuse, 38.4\% of respondents reported being sexually abused before age 17 , with over half of these participants indicating that their most severe form of sexual abuse included intercourse. The mean duration of sexual abuse experiences was 3.32 years. Extended family members (63\%) and ac- 
Table 1

Abuse characteristics of participants $(N=112)$

\begin{tabular}{|c|c|c|c|}
\hline & $n$ & Abused sample (\%) & Total sample (\%) \\
\hline \multicolumn{4}{|l|}{ Sexual abuse sample $(n=43)$} \\
\hline Presence of sexual abuse & 43 & & 38.4 \\
\hline \multicolumn{4}{|l|}{ Most severe form experienced } \\
\hline Fondling & 21 & 48.8 & 18.8 \\
\hline Intercourse & 22 & 51.2 & 19.6 \\
\hline \multicolumn{4}{|l|}{ Total number of perpetrators } \\
\hline 1 & 30 & 69.8 & 26.8 \\
\hline 2 & 9 & 20.9 & 8.0 \\
\hline 3 & 4 & 9.3 & 3.6 \\
\hline \multicolumn{4}{|l|}{ Force used } \\
\hline Yes & 15 & 34.9 & 13.4 \\
\hline No & 28 & 65.1 & 25.0 \\
\hline \multicolumn{4}{|l|}{ Offenderi } \\
\hline Father figure $^{\mathrm{h}}$ & 4 & 9.3 & 3.6 \\
\hline Other nuclear family ${ }^{\mathrm{c}}$ & 2 & 4.7 & 1.8 \\
\hline Extended family & 27 & 62.8 & 24.1 \\
\hline Acquaintance & 24 & 55.8 & 21.4 \\
\hline Stranger & 2 & 4.7 & 1.8 \\
\hline Other & 1 & 2.3 & .9 \\
\hline \multicolumn{4}{|l|}{ Physical abuse sample $(n=12)$} \\
\hline Presence of physical abuse & 12 & & 10.7 \\
\hline \multicolumn{4}{|l|}{ Frequency } \\
\hline$<10$ times & 6 & 50.0 & 5.4 \\
\hline 10-49 times & 1 & 8.3 & 0.9 \\
\hline$\geq 50$ times & 4 & 33.3 & 3.6 \\
\hline Missing & 1 & 8.3 & 0.9 \\
\hline \multicolumn{4}{|l|}{ Duration } \\
\hline$<1$ year & 3 & 25.0 & 2.7 \\
\hline $1-4$ years & 4 & 33.3 & 3.6 \\
\hline$\geq 5$ years & 5 & 41.7 & 4.5 \\
\hline Medical treatment needed & 3 & 25.0 & 2.7 \\
\hline \multicolumn{4}{|l|}{ Witnessing abuse sample $(n=38)$} \\
\hline Presence of witnessed abuse & 38 & & 33.9 \\
\hline \multicolumn{4}{|l|}{ Frequency } \\
\hline $1-5$ times & 24 & 63.2 & 21.4 \\
\hline $6-10$ times & 3 & 7.9 & 2.7 \\
\hline $11-25$ times & 2 & 5.3 & 1.8 \\
\hline Unable to estimate & 8 & 21.1 & 7.1 \\
\hline Not reported & 1 & 2.6 & 0.9 \\
\hline \multicolumn{4}{|l|}{ Violence direction } \\
\hline Father $\rightarrow$ Mother & 34 & 89.5 & 30.4 \\
\hline Mother $\rightarrow$ Father & 22 & 57.9 & 19.6 \\
\hline
\end{tabular}


Table 1 (Continued)

\begin{tabular}{llll}
\hline & $n$ & Abused sample (\%) & Total sample \\
\hline Bi-directional & 18 & 47.4 & 16.1 \\
$\quad$ Medical treatment /police involvement & 18 & 47.4 & 16.1 \\
Emotional abuse scores $(n=112)$ & & & \\
& $M$ & $S D$ & \\
\hline Total emotional abuse score $^{\mathrm{d}}$ & 2.5 & 1.6 & \\
Yell at you & 4.6 & 1.5 & \\
Insult you & 2.1 & 2.2 & \\
Criticize you & 2.9 & 2.1 & \\
Try to make you feel guilty & 2.8 & 2.1 & \\
Ridicule or humiliate you & 1.6 & 2.0 & \\
Embarrass you in front of others & 1.9 & 2.0 & \\
Make you feel like you were a bad person & 1.5 & 2.3 & \\
\hline
\end{tabular}

${ }^{a}$ Total number of offenders is greater than the number of victims due to multiple perpetrators for some vict

${ }^{\mathrm{b}}$ Includes Father, Step-father, and Foster father.

${ }^{\mathrm{c}}$ Includes Mother, Siblings, Step-siblings, Half-siblings, Foster mother, and Guardian/foster parent with no specified.

${ }^{\mathrm{d}}$ Scale: $0=$ never, $1=$ once a year, $2=$ twice a year, $3=3-5$ times a year, $4=6-10$ times a year, $5=11$ times a year, $6=$ over 20 times a year.

quaintances $(56 \%)$ were the most common perpetrators of the sexual abuse in the sample. It is also noteworthy that $35 \%$ of those who were sexually abused also reported incidents that included the use of physical force. With respect to physical abuse, $11 \%$ reported experiencing physically abusive acts committed by their parents or a parental figure. Of those classified as physically abused, $50 \%$ indicated that the abuse occurred less than 10 times, while $33 \%$ reported this type of maltreatment on at least 50 occasions. One in four persons in this subsample also indicated they had sustained abuse-related injuries severe enough to require medical attention. Regarding exposure to parental violence, $34 \%$ of the total sample endorsed the following item: "Before age 17, did you ever see one of your parents hit or beat up your other parent?" The majority of these participants (63\%) indicated that they had been exposed to parental violence five times or less, while another $20 \%$ witnessed this type of abuse so frequently that they were unable to provide an accurate estimate. Of those exposed to domestic violence, $89 \%$ reported witnessing their father hit their mother. Equal proportions $(47 \%$ each) of those witnessing abuse reported viewing bi-directional violence between parents or witnessing violence that necessitated medical treatment or police involvement. Regarding emotional abuse, $27 \%$ of the sample met the criteria for this type of maltreatment. Table 1 contains the mean scores by item for the entire sample.

\section{Co-occurrence of maltreatment types}

As noted, in order to calculate the co-occurrence of the various forms of maltreatment, a summary score was created that reflected the total number of maltreatment types experienced by each participant. Thus, every participant received a score ranging from $0=$ 
Table 2

Acculturation characteristics of the sample $(n=112)$

\begin{tabular}{lc}
\hline & Total (\%) \\
\hline Level I-Very Mexican oriented & 0.9 \\
Level II-Mexican oriented to approximately balanced bicultural & 13.4 \\
Level III-Slightly Anglo oriented bicultural & 50.9 \\
Level IV-Strongly Anglo oriented & 29.5 \\
Level V-Very assimilated; Anglicized & 5.4 \\
\hline
\end{tabular}

"no abuse" to 4 = "all four types of abuse. " The distribution of these scores for the entire sample are as follows: $32.1 \%$ reported experiencing no maltreatment; $39.3 \%$ experienced a single type of child maltreatment; $17.9 \%$ experienced two types; $7.1 \%$ experienced three; and $3.6 \%$ experienced all four.

\section{Trauma symptomatology and acculturation characteristics of the sample}

The mean TSC total score for all participants was $31.8(S D=17.1)$, with a range of $0-84$ out of 120 total points possible. This score is substantially higher than the mean of $22.3(S D=11.6)$ reported for the TSC normative sample (Elliott \& Briere, 1992). Table 2 depicts the distribution of acculturation scores for the sample across the five levels of linear acculturation set forth by the ARSMA-II. As suggested by Cuellar et al. (1995), the ARSMA-II linear acculturation scores were treated as a classification variable used to group individuals into five levels of acculturation. Cutoff scores provided by the scale authors and based on the original normative sample were used to classify participants into one of five acculturation levels ranging from Level 1 ("Very Mexican oriented") to Level 5 ("Very assimilated; Anglicized"). Table 2 shows a relatively normal distribution of acculturation scores, with $51 \%$ of participants falling within Level 3 ("Slightly Anglo oriented bicultural"). Because only one individual was classified as "Very Mexican oriented," this person was included in Level 2 for the purpose of analyses.

\section{Cumulative impact of maltreatment and acculturation on trauma symptoms}

A factorial analysis of variance was conducted using the total number of maltreatment types experienced $(0,1$, or 2 or more forms of maltreatment) and the different levels of acculturation (1-5) as independent variables, and respondents' TSC scores as the dependent variable. The ANOVA results are presented in Table 3, with the means and standard deviations for all groups shown in Table 4 . As shown in the Table 3, there was a main effect for number of maltreatment types on TSC scores, $F(2,100)=3.18, p<.05$. Tukey post hoc tests revealed significant differences between the TSC scores of those who experienced two or more maltreatment types and no maltreatment $(p<.01)$, as well as between those with two or more types of maltreatment versus a single form $(p<.05)$. However, no differences were found between the TSC scores of those with one maltreatment type and those who had not been maltreated at all. That is, persons who met the criteria for at least two forms of maltreatment reported significantly more trauma symptoms than 
Table 3

Summary of factorial analysis of variance for number of abuse types and acculturation level as related to TSC scores

\begin{tabular}{lrrrc}
\hline Variable & \multicolumn{1}{c}{$d f$} & \multicolumn{1}{c}{$S S$} & \multicolumn{1}{c}{$M S$} & \multicolumn{1}{c}{$F$} \\
\hline Number of abuse types & 2 & 1751.99 & 876.00 & $3.18^{*}$ \\
Acculturation level & 3 & 813.09 & 271.03 & .98 \\
Number of abuse types $\times$ acculturation level & 6 & 632.00 & 105.33 & .38 \\
Within cells & 100 & 27564.60 & 275.65 & \\
Total & 111 & 32373.48 & & \\
\hline
\end{tabular}

${ }^{*} p<.05$.

those reporting a single type of maltreatment or none at all. No relationship was found between acculturation level and trauma symptom scores, $F(3,100)=.98, p=.40$, nor was there an interaction effect between the number of types of maltreatment and acculturation as they relate to trauma symptomatology, $F(6,100)=.89, p=.89$.

\section{Maltreatment severity}

Given this pattern of TSC score differences, we also examined whether the severity of maltreatment varied across groups experiencing either one or two or more types of maltreatment. To do this, we considered several indicators of severity for individual maltreatment types within each group. Table 5 illustrates Chi-square and $t$ test results for these analyses. Across all individual maltreatment types, a pattern emerged in which participants with two or more forms of maltreatment reported experiencing more severe maltreatment than those with single types. Within the sexual abuse sample, participants with

Table 4

Mean TSC scores and standard deviations of participants by acculturation level and abuse status

\begin{tabular}{|c|c|c|c|c|c|c|}
\hline & \multicolumn{6}{|c|}{ Number of abuse types } \\
\hline & \multicolumn{2}{|c|}{ None $(n=36)$} & \multicolumn{2}{|c|}{ One $(n=44)$} & \multicolumn{2}{|c|}{ Two or more $(n=32)$} \\
\hline & $M$ & $S D$ & $M$ & $S D$ & $M$ & $S D$ \\
\hline Level II ${ }^{\mathrm{a}}$ & 31.5 & 21.8 & 29.8 & 20.6 & 46.5 & 10.1 \\
\hline \multicolumn{7}{|c|}{ Mexican oriented to approximately balanced bicultural } \\
\hline Level III & 26.2 & 13.4 & 29.0 & 13.9 & 42.7 & 19.5 \\
\hline \multicolumn{7}{|c|}{ Slightly Anglo oriented; bicultural } \\
\hline Level IV & 28.2 & 17.7 & 30.7 & 15.4 & 34.0 & 22.7 \\
\hline \multicolumn{7}{|c|}{ Strongly Anglo oriented } \\
\hline Level V & 13.5 & 6.4 & 25.3 & 7.4 & 29.5 & 10.6 \\
\hline \multicolumn{7}{|c|}{ Very assimilated; Anglicized } \\
\hline Total & 26.9 & 15.8 & 29.5 & 14.6 & 40.3 & 18.9 \\
\hline
\end{tabular}

\footnotetext{
a The one person classified as Level I "Very Mexican oriented" was included in Level II for the purposes of analyses. See text.
} 
Table 5

Prevalence $(\%)$ or mean values of severity indicators among participants with one and two or more abuse types

\begin{tabular}{|c|c|c|c|}
\hline \multirow[t]{2}{*}{ Severity indicator } & \multicolumn{3}{|c|}{ Number of abuse types } \\
\hline & $\begin{array}{l}\text { One } \\
(n=44)\end{array}$ & $\begin{array}{l}\text { Two or more } \\
(n=32)\end{array}$ & $\chi^{2}(1)$ or $t$ \\
\hline \multicolumn{4}{|l|}{ Sexual abuse sample } \\
\hline Intercourse & 18.2 & 43.8 & $5.89^{*}$ \\
\hline Force used & 6.8 & 37.5 & $11.01^{* * *}$ \\
\hline Duration (in years) & 1.7 & 4.4 & $3.12^{* *}$ \\
\hline \multicolumn{4}{|l|}{ Physical abuse sample } \\
\hline$\geq 3$ Occurrences & 6.8 & 18.8 & 2.53 \\
\hline Medical treatment needed & 0.0 & 9.4 & 4.30 \\
\hline \multicolumn{4}{|l|}{ Witnessing abuse sample } \\
\hline$\geq 3$ Occurrences & 27.3 & 46.9 & 3.11 \\
\hline Medical treatment needed & 15.9 & 34.4 & 3.50 \\
\hline \multicolumn{4}{|l|}{ Emotional abuse sample } \\
\hline \multicolumn{4}{|l|}{ Total emotional abuse score } \\
\hline$M$ & 4.2 & 5.1 & $3.71^{* * *}$ \\
\hline$S D$ & .49 & .68 & \\
\hline
\end{tabular}

Note. $t$ test used for sexual abuse duration and emotional abuse means; Chi-square used for all other variables.

${ }^{*} p<.05$.

${ }^{* *} p<.01$

${ }^{* * *} p<.001$.

two or more maltreatment types were more likely to report penetration, the use of physical force, and a longer mean duration as a part of their sexual abuse experiences than were their counterparts in the single abuse type category. Among those classified as emotionally abused, those reporting two or more types of maltreatment had significantly higher mean scores than did those experiencing single forms of maltreatment. Although group differences (one vs. two or more maltreatment types) were not statistically significant within the physical abuse and witnessing abuse categories, the general pattern of increasing severity for greater numbers of abuse types remained the same.

\section{Discussion}

The present investigation extends findings from studies of "multi-type" abuse with non- Hispanic, Caucasian samples (Briere \& Runtz, 1990; Higgins \& McCabe, 2000; Moeller et al., 1993; Ney et al., 1994) by suggesting that Latina college students may also commonly experience multiple forms of maltreatment during childhood. In the present study, $29 \%$ of participants reported being subjected to two or more forms of maltreatment as children. Furthermore, as predicted, those who endured multiple forms of maltreatment reported more trauma symptoms than did those experiencing a single form of abuse or none at all. It should be noted, however, that the increased symptomatology reported by those who were multiply abused may not be solely a function of the number of maltreat- 
ment types experienced, for these participants also reported more severe maltreatment characteristics within each type (e.g., more severe sexual abuse involving penetration and physical force, emotional abuse that was more intense and frequent). This suggests a family environment in which increased types of maltreatment are accompanied by a corresponding escalation in the seriousness and severity of the acts committed.

It is noteworthy that the level of trauma symptomatology experienced by participants in the present study was substantially higher than that reported for the TSC normative sample (mean scores of 31.8 and 22.3, respectively; Elliott \& Briere, 1992). Several differences in sample characteristics may account for this disparity. The present sample contained a greater proportion of sexual abuse survivors (39\% vs. 27\%), despite the fact that both studies used almost identical criteria to define this type of maltreatment. This increased rate of CSA may well have contributed to the greater symptomatology in the current sample. Participant age and socioeconomic status may also have contributed to the differing trauma symptoms. The mean age of our sample was 22.6 years, while Elliott and Briere (1992) reported a mean age of 41.7 for their participants. In addition, most participants in the current study were of a lower-middle to middle SES, while the average SES within the standardization group was middle to upper-middle class. The possible relevance of these demographic differences is highlighted by Elliott and Briere's (1992) findings that, although TSC scores in their normative sample were unrelated to race, marital status, or education, trauma symptom levels were negatively correlated with both age and income.

An interesting yet unexpected finding was that the 39\% of participants who experienced a single form of child maltreatment did not, as a group, report greater adult trauma symptomatology than did individuals who reported no maltreatment. This is surprising in light of the abundant literature documenting associations between individual types of maltreatment, such as sexual abuse, and the presentation of symptoms in adulthood in both Caucasian (see Polusny \& Follette, 1995 for a review) and Latino samples (Arroyo et al., 1997; Mennan, 1994) using the TSC (Elliott \& Briere, 1992) and similar adult outcome measures (Allen, Coyne, \& Huntoon, 1998). It is possible that the severity of maltreatment experienced by those in the single maltreatment group did not reach a threshold needed to produce lasting negative outcomes that could be detected through completion of the TSC. For example, as noted earlier, a comparatively smaller proportion of survivors in the single maltreatment group reported that penetration or the use of physical force was apart of their sexually abusive experiences. Another possible reason for the inconsistency with past findings is that prior investigations have rarely assessed more than a single abuse type. That is, with few exceptions (e.g., Briere \& Runtz, 1990; Wind \& Silvern, 1992) previous work has inquired about a particular form of maltreatment, while ignoring other types of child abuse that may independently contribute to long-term adjustment difficulties. This practice of focusing on a single form of maltreatment to the exclusion of others leaves open the possibility that the adult adjustment problems reported by participants may, in part, be a function of the cumulative impact of multiple types of maltreatment, some of which were not assessed in those studies. Thus, in the absence of a thorough assessment of multiple forms of maltreatment, those abuse types that are not assessed may confound inferences about the association between any single form and later functioning.

Acculturation status was also examined as a possible factor in the development of adult symptomatology. Of particular interest was the possibility that acculturation level 
might interact with maltreatment history to moderate adult outcomes. This relationship as well as any direct association between acculturation and long-term adjustment was not supported. Therefore, it appears that the behavioral and affective factors underlying one's degree of affiliation with Mexican versus Anglo culture did not playa significant role in long-term adjustment following maltreatment. However, it should be noted that our sample (with the exception of one individual) did not contain participants who were categorized as "very Mexican oriented." Thus, greater variability on this dimension may have revealed associations between acculturation, maltreatment, and adult adjustment that were not found here.

\section{Study limitations}

The present study has limitations that should be considered. One problem faced by many child maltreatment researchers concerns the use of retrospective reporting. Except in the atypical instances in which a longitudinal design or access to archival records are possible, data on the presence and characteristics of childhood maltreatment is typically gathered from adults by use of a retrospective self-report measure. Although unavoidable in most circumstances, this common method is subject to errors in recall, intentionally false responses (either false positives or false negatives), and, depending on one's belief in the claims, the inaccessibility of memories for traumatic abuse. Together, these factors may reduce the reliability and validity of the maltreatment data collected. Another limitation of the present study involves the use of a college sample. Despite being the most well-studied group within the child maltreatment literature (Rind, Bauserman, \& Tromovitch, 1998), samples of college students have limited variance in terms of age, education, and often, socioeconomic status. Thus, use of a college sample in the current investigation may limit the generalizability of the present results to Mexican American females with similarly restricted demographics. Therefore, although this research expanded on the range of ethnic groups in which the co-occurrence of maltreatment types has been examined, the applicability of these findings to the larger Latino population cannot be assumed.

\section{Study implications}

Despite these limitations, the present data have implications for future research with maltreated populations. This study revealed not only a high co-occurrence among different forms of maltreatment, but also that greater numbers of maltreatment types were associated with increased abuse severity and trauma symptomatology among Latina participants. These findings highlight the need for future research to examine the presence and impact of concomitant forms of maltreatment across diverse populations. Consideration of maltreatment severity, rather than just occurrence, is also important when attempting to draw conclusions about the possible long-term effects of various childhood maltreatment experiences. Here, the scope of the study was limited to adult trauma symptomatology. However, the potential impact of multiple forms of child maltreatment on other facets of adult adjustment has yet to be explored. Existing research suggests that individual types of child maltreatment may be associated with .a variety of intrapersonal and interpersonal difficulties (DiLillo, 2001; Malinosky-Rummell \& Hansen, 1993; Polusny \& 
Follette, 1995; Whipple \& Webster-Stratton, 1991). Given the growing body of literature suggesting an additive impact of multiple forms of maltreatment, a logical next step may be to explore the potential impact of co-occurring maltreatment types on a wider range of adult functioning in Latino and other populations.

\section{References}

Allen, J. G., Coyne, L., \& Huntoon, J. (1998). Trauma pervasively elevates Brief Symptom Inventory profiles in inpatient women. Psychological Reports, 83, 499-513.

American Psychological Association. (1992). Ethical principles of psychologists. American Psychologist, 47, $1597-1611$.

Arroyo, J. A., Simpson, T. L., \& Aragon, A. S. (1997). Childhood sexual abuse among Hispanic and non-Hispanic White college women. Hispanic Journal of Behavioral Sciences, 19, 57-68.

Appel, A. E., \& Holden, G. W. (1998). The co-occurrence of spouse and physical child abuse: A review and appraisal. Journal of Family Psychology, 12, 578-599.

Behl, L. E., Crouch, J. L., May, P. P., Valente, A. L., \& Conyngham, H. A. (2001). Ethnicity in child maltreatment research: A content analysis. Child Maltreatment, 6(2), 143-147.

Briere, J. (1992). Child abuse trauma: Theory and treatment of the lasting effects. Newbury Park, CA: Sage Publications.

Briere, J., \& Runtz, M. (1988). Multivariate correlates of childhood psychological and physical maltreatment among university women. Child Abuse \& Neglect, 12, 331-341.

Briere, J., \& Runtz, M. (1989). The Trauma Symptom Checklist (TSC-33). Early data on a new scale. Journal of Interpersonal Violence, 8, 151-163.

Briere, JI., \& Runtz, M. (1990). Differential adult symptomatology associated with three types of child abuse histories. Child Abuse \& Neglect, 14, 357-364.

Champion, J. D. (1999). Effect of abuse on self-perception of rural Mexican-American and non-Hispanic White adolescents. Archives of Psychiatric Nursing, 13(1). 12-18.

Claussen, A. H., \& Crittenden, P. M. (1991). Physical and psychological maltreatment: Relations among types of maltreatment. Child Abuse \& Neglect, 15, 5-18.

Chrestman, K. R. (1995). Secondary exposure to trauma and self reported distress among therapists. In B. H. Stamm (Ed.), Secondary traumatic stress: Self-care issues for clinicians, researchers, and educators (pp. 29-36). Lutherville, MD: The Sidran Press.

Cuéllar, I., Arnold, B., \& Maldonado, R. (1995). Acculturation Rating Scale for Mexican-Americans-II: A revision of the original ARSMA scale. Hispanic Journal of Behavioral Sciences, 17, 275-304.

Cuéllar, I., \& Roberts, R. E. (1997). Relations of depression, acculturation, and socioeconomic status in a Latino sample. Hispanic Journal of Behavioral Sciences, 19, 230-238.

DiLillo, D. (2001). Interpersonal functioning among women reporting a history of child sexual abuse: Empirical findings and methodological issues. Clinical Psychology Review, 21, 553-576.

Dutton, D. G. (1995). Trauma symptoms and PTSD-like profiles in perpetrators of intimate violence. Journal of Traumatic Stress, 8, 299-316.

Elliott, D. M., \& Briere, J. (1992). Sexual abuse trauma among professional women: Validating the Trauma Symptom Checklist-40. Child Abuse \& Neglect, 16, 391-398.

Fontes, L. A. (1995). Sexual abuse in nine North American cultures: Treatment and interventions. Thousand Oaks, CA: Sage.

Higgins, D. J., \& McCabe, M. P. (2000). Multi-type maltreatment and the long-term adjustment of adults. Child Abuse Review, 9, 6-18.

Hollingshead, A. B. (1975). Four Factor Index of Social Position. Unpublished manuscript, New Haven, CT.

Hughes, H. M., Parkinson, D., \& Vargo, M. (1989). Witnessing spouse abuse and experiencing physical abuse: A “double whammy?" Journal of Family Violence, 4, 197-209. 
Huston, R. L., Parra, J. M., Prihoda, T. J., \& Poulds, D. M. (1995). Characteristics of childhood sexual abuse in a predominantly Mexican-American population. Child Abuse \& Neglect, 19(2), 165-176.

Lefley, H. P., Scott, C. S., Llabre, M., \& Hicks, D. (1993). Cultural beliefs about rape and victims response in three ethnic groups. American Journal of Orthopsychiatry, 63, 623-632.

Malinosky-Rummell, R., \& Hansen, D. J. (1993). Long-term consequences of childhood physical abuse. Psychological Bulletin, 114, 68-79.

Mannarino, A. P., Cohen, J. A., \& Gregor, M. (1989). Emotional and behavioral differences in sexually abused girls. Journal of Interpersonal Violence, 4, 437-451.

Mennan, F. E. (1994). Sexual abuse in Latina girls: Their functioning and a comparison with White and African-American girls. Hispanic Journal of Behavioral Sciences, 16, 475-486.

Moeller, T. P., Bachmann, G. A., \& Moeller, J. R. (1993). The combined effects of physical, sexual and emotional abuse during childhood: Long-term health consequences for women. Child Abuse \& Neglect, 17, 623-640.

Morrow, K. B., \& Sorrell, G. T. (1989). Factors affecting self-esteem, depression and negative behaviors in sexually abused female adolescents. Journal of Marriage and the Family, 51, 677-686.

Ney, P. G., Fung, T., \& Wickett, A. R. (1994). The worst combinations of child abuse and neglect. Child Abuse \& Neglect, 18, 705-714.

Polusny, M. M., \& Follette, V. M. (1995). Long-term correlates of childhood sexual abuse: Theory and empirical findings. Applied and Preventive Psychology, 4, 143-166.

Ramos Lira, L., Koss, M. P., \& Russo, N. F. (1999). Mexican American women's definitions of rape and sexual abuse. Hispanic Journal of Behavioral Sciences, 21, 236-265.

Rind, B., Bauserman, R., \& Tromovitch, P. (1998). A meta-analytic examination of assumed properties of child sexual abuse using college samples. Psychological Bulletin, 124, 22-53.

Rogler, L. H., Cortes, D. E., \& Malgady, R. G. (1991). Acculturation and mental health status among Hispanics: Convergence and new directions for research. American Psychologist, 46, 585-597.

Roosa, M. W., Reinholtz, C., \& Angelini, P. J. (1999). The relation of child sexual abuse and depression in young women: Comparisons across four ethnic groups. Journal of Abnormal Child Psychology, 27(1), 65-76.

Sanders-Phillips, K., Moisan, P. A., Wadlington, S., Morgan, S., \& English, K. (1995). Ethnic differences in psychological functioning among Black and Latino sexually abused girls. Child Abuse \& Neglect, 19(6), 691706.

Schaff, K. K., \& McCanne, T. R. (1998). Relationship of childhood sexual, physical, and combined sexual and physical abuse to adult victimization and posttraumatic stress disorder. Child Abuse \& Neglect, 22, 1119-1133.

Schechter, D. S., Marshall, R., Salman, E., Goetz, D., Davies, S., \& Liebowitz, M. R. (2000). Ataque de nervios and history of childhood trauma. Journal of Traumatic Stress, 13(3), 529-534.

Sorenson, S. B., \& Siegel, J. M. (1992). Gender, ethnicity, and sexual assault: Findings from a Los Angeles study. Journal of Social Issues, 48(1), 93-104.

Stein, J. A., Golding, J. M., Siegel, J. M., Burnam, M. A., \& Sorenson, S. (1988). Long-term psychological sequelae of child sexual abuse: The Los Angeles Epidemiologic Catchment Area Study. In G. Wyatt \& G. Powell (Eds.), Lasting effects of child sexual abuse (pp. 134-135). Newbury Park, CA: Sage.

Sue, D. W., \& Sue, D. (1999). Counseling Hispanic Americans. In Counseling the culturally different (pp, 286-303). United States Census Bureau. (2001). Race and Hispanic or Latino summary file [On-line]. Available: Retrieved October 16,2001 from http:/www.census.gov/prod/cen2000/doc/racehislat.pdf

Westen, D., Ludolph, P., Misle, B., Ruffins, S., \& Block, J. (1990). Physical and sexual abuse in adolescent girls with borderline personality disorder. American Journal of Orthopsychiatry, 60, 55-66.

Whipple, E. E., \& Webster-Stratton, C. (1991). The role of parental stress in physically abusive families. Child Abuse \& Neglect, 15, 279-291.

Wind, T. W., \& Silvern, L. (1992). Type and extent of child abuse as predictors of adult functioning, Journal of Family Violence, 7, 261-281. 


\section{Resume}

Objectifs: Cette étude avait deux buts: d'abord, d'examiner la nature et la co-existence de diverses formes de mauvais traitements envers les enfants (sexuel, physique, émotionnel et à titre de témoin d'une agression) telles que signalés par des collégiens latino-américains; et deuxièmement, d'explorer l'acculturation et les types de mauvais traitements qui peuvent co-exister, en tant que facteurs pouvant contribuer à des difficultés d'adaptation à long terme.

Méthode: Les participants de l'étude étaient 112 étudiants latino-américains de second cycle qui ont été classés selon la fréquence des mauvais traitements vécus $(0,1$, ou 2 ou plus) et leur niveau d'acculturation (1 à 5). Les enquêteurs ont examiné comment l'acculturation et la présence simultanée de plusieurs formes de mauvais traitements peuvent agir sur les symptômes de traumatisme que rapportent ces étudiants. Les données ont été recueillies à partir de renseignements foumis par les étudiants.

Résultats: près de 3 sur 10 participants $(29 \%)$ ont connu plus d'une forme de mauvais traitements. Il n'était pas surprenant de retrouver chez ces jeunes des symptômes de traumatismes plus importants que chez les participants qui n'ont connu qu'un type de mauvais traitement ou qui n'ont jamais été victimes du tout. Parmi ceux qui disent avoir connu plusieurs formes de mauvais traitements, ces mauvais traitements sont plus graves que ceux qu'on retrouve chez les victimes d'un seul type d'agression. Le niveau d'acculturation ne semble pas agir directement sur les symptômes de traumatisme ni sur les effets à long terme. Il est intéressant de noter que ceux qui ont vécu une seule forme de mauvais traitements ne rapportent pas plus de symptômes que ceux qui n'ont jamais été maltraités.

Conclusion: Cette enquête indique un chevauchement.considérable des divers types de mauvais traitements chez une population de collégiens latino-américains. Les résultats soulignent l'importance de prendre en considération les formes multiples de mauvais traitements ainsi que leur gravité, lorsque vient le temps de prévoir les effets possibles à long terme.

\section{Resumen}

Objetivos: Este estudio tenía dos objetivos primarios: Primero, examinar la naturaleza y co-ocurrencia de varias formas de maltrato infantil (sexual, físico, emocional, y ser testigos de violencia) reportados por estudiantes de universidad latinas; y segundo, explorar los tipos de malos tratos existentes y el status de aculturación coexistente como posibles contribuyentes de dificultades en el ajuste a largo plazo.

Método: Los participantes fueron 112 estudiantes de universidad latinas clasificadas por el número de tipos de maltrato infantil ( 0,1 , o 2 o más) y nivel de aculturación (1 a 5). Se investigaron los posibles efectos de formas de maltrato co-ocurrentes, en conjunto con el status de aculturación con relación a la sintomatología del trauma reportada por los participantes. Los datos fueron recolectados utilizando medidas de auto-reporte.

Resultados: Casi tres de cada 10 participantes (29\% ) sufrieron más de un tipo de maltrato infantil y, como se esperaba, estas personas reportaron mayor sintomatología que aquellas que reportaron un solo tipo de maltrato o ningún maltrato. Aquellas que reportaron múltiples malos tratos también sufrieron malos tratos más severos que las que sufrieron un solo tipo. El nivel de aculturación no estaba ni directamente relacionado con los síntomas del trauma ni disminuía los efectos permanentes en las víctimas de malos tratos. Es interesante notar que las que sufrieron una sola forma de maltrato no reportaron más síntomas del trauma que las participantes que reportaron no tener ninguna historia de maltrato.

Conclusión: Esta investigación documenta un alto grado de superposición entre varias formas de maltrato infantil reportado por la población de estudiantes universitarias latinas. Los resultados subrayan la necesidad de considerar múltiples formas de malos tratos, así como la severidad, cuando se realicen inferencias con relaciín a efectos potenciales sobre el funcionamiento posterior. 